\title{
Comparison of Effects of Triple Antibiotic Paste , Double Antibiotic Paste and Proton Pump Inhibitor on E. faecalis- An Invitro Study
}

\author{
Anupama Deepak ${ }^{1}$ and Delphine Priscilla Antony. $\mathrm{S}^{2}$ \\ ${ }^{1}$ Saveetha Dental College, Saveetha Dental College and Hospitals Saveetha Institute \\ of Medical and Technical Sciences Saveetha University, Chennai 600077, India \\ ${ }^{2}$ Senior Lecturer Department of Conservative Dentistry and Endodontics, Saveetha Dental College \\ and Hospitals Saveetha Institute of Medical and Technical Sciences Saveetha University, \\ Chennai 600077, India
}

\section{ABSTRACT}

Endodontic therapy is mainly done for complete elimination of the root canal pathogens within the root canal system. Triple antibiotic paste and double antibiotic paste are one of the intracanal medicaments that are used for root canal disinfection. They are known for complete microbial suppression of root canal pathogens. Endodontic instrumentation with irrigants alone cannot achieve a sterile condition. Therefore, the aim of this study is to compare the effects of triple antibiotic paste, double antibiotic paste and a proton pump inhibitor on E.faecalis.

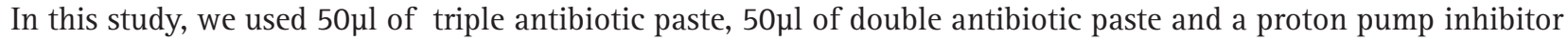
(pantoprazole). These antibiotics were then incubated at $37^{\circ} \mathrm{C}$ and were tested against the bacterial strains of E.faecalis. The percentage of microbial inhibition was found and the results were then expressed as the mean percentage of microbial inhibition at $12 \mathrm{~h}$ and $24 \mathrm{~h}$ respectively. The results were statistically significant as compared with TAP group and the DAP group $(\mathrm{p}<0.001)$. Therefore, TAP and DAP were found to be equally effective against E.faecalis, but TAP+PPi was found to have a higher percentage of inhibition than TAP and DAP.

KEY WORDS: TRIPLE ANTIBIOTIC PASTE, DOUBLE ANTIBIOTIC PASTE, INHIBITION, E.FAECALIS.

\section{INTRODUCTION}

Root canal treatment is a procedure for elimination of bacteria from the infected root canal (Pinky, Subbareddy and Shashibhushan, 2011). The infection of the root canal system is a multifactorial bacterial infection, consisting of aerobic and anaerobic bacteria, most of them being

\section{ARTICLE INFORMATION}

*Corresponding Author: delphine.sdc@saveetha.com Received 27th June 2020 Accepted after revision 4th August 2020 Print ISSN: 0974-6455 Online ISSN: 2321-4007 CODEN: BBRCBA

Thomson Reuters ISI Web of Science Clarivate Analytics USA and Crossref Indexed Journal

$$
1 \text { Clarivate crossef }
$$

NAAS Journal Score 2020 (4.31) SJIF: 2020 (7.728)

A Society of Science and Nature Publication,

Bhopal India 2020. All rights reserved.

Online Contents Available at: http//www.bbrc.in/

Doi: $h$ ttp://dx.doi.org/10.21786/bbrc/13.7/35 the obligate anaerobes. Bacteria in the infected root canals and periradicular tissues can invade through the cementum and dentin to the periapical region leading to infection of the periapex. A wide range of intra canal medicaments have been used such as the Calcium hydroxide paste, Chlorhexidine gel, Triple antibiotic paste, and Double antibiotic paste. Calcium hydroxide plays an important role as it has the ability to induce hard tissue formation, antibacterial property and tissue dissolving capability (Nerwich, Figdor and Messer, 1993).

A single antibiotic may produce ineffective sterilisation of the root canal system. Therefore, a combination of one or more antibiotics can result in the elimination of the bacteria (Windleyiii et al., 2005). Metronidazole

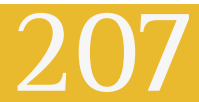


was the first antibiotic drug used, but since it cannot kill all the bacteria, a combination of drugs were used. There are numerous ways to eliminate the microbial colonies from the root canal system such as various instrumentation techniques (Mohammadi et al., 2013), irrigation techniques (Mohammadi, Shalavi, et al., 2015; Mohammadi et al., 2017) and intracanal medicaments (Mohammadi, Giardino, et al., 2015).

One of the widely used intracanal medicaments combination is the triple antibiotic paste consisting of metronidazole, ciprofloxacin, and minocycline, due to its antimicrobial properties in endodontic regenerative procedures (Sato et al., 1996; Windleyiii et al., 2005)). Double antibiotic paste is another antibiotic consisting of ciprofloxacin and metronidazole, which is mainly known for its treatment in external resorption. Traditionally used intracanal medicament was the calcium hydroxide to induce apexification at the root apex. Tetracycline belongs to a group of broad-spectrum antibiotics which are effective against a wide range of microorganisms that are bacteriostatic in nature.

Metronidazole is also a broad spectrum antibiotic that is effective against protozoa, anaerobic cocci and gramnegative and gram-positive bacilli. Studies show that $2 \%$ metronidazole gel was used for disinfection of dentinal tubules and this metronidazole gel was more efficient than bioactive glass and calcium hydroxide for disinfection (Krithikadatta, Indira and Dorothykalyani, 2007). Ciprofloxacin is a second-generation fluoroquinolone antibiotic that is effective against most strains including Escherichia coli, Legionella pneumophila, Haemophilus influenzae, Klebsiella pneumoniae, etc (Drusano et al., 1986). Proton pump inhibitors are drugs that inhibit the production of acid by the stomach and are commonly used in the treatment of gastroesophageal reflux disease (GERD), peptic ulcer disease, and infection in the stomach with Helicobacter pylori.

Endodontic regeneration can occur from various sources like the vital pulp cells in the root canal, the stem cells in the dental pulp , periodontal ligament from apical papilla (Saad and Yousef Saad, 1988; Gronthos et al., 2002; Cotti, Mereu and Lusso, 2008). Radiographic evaluation reveals the successfulness of endodontic treatment performed (Antony, Thomas and Nivedhitha, 2020). We have numerous highly cited publications on well designed clinical trials and lab studies (Govindaraju, Neelakantan and Gutmann, 2017; Azeem and Sureshbabu, 2018; Jenarthanan and Subbarao, 2018; Manohar and Sharma, 2018; Nandakumar and Nasim, 2018; Teja, Ramesh and Priya, 2018; Janani and Sandhya, 2019; Khandelwal and Palanivelu, 2019; Malli Sureshbabu et al., 2019; Poorni, Srinivasan and Nivedhitha, 2019; Rajakeerthi and Ms, 2019; Rajendran et al., 2019; Ramarao and Sathyanarayanan, 2019; Siddique and Nivedhitha, 2019;
Siddique et al., 2019; Siddique, Nivedhitha and Jacob, 2019). This has provided the right platforms for us to pursue the current study. Our aim was to compare the effects of triple antibiotic paste, double antibiotic paste and a proton pump inhibitor on E.faecalis.

\section{MATERIAL AND METHODS}

\section{Chemicals:}

1. Pantoprazole (PPIs )- pantoprazole was mixed with deionised water at a concentration of $1 \mathrm{mg} /$ $\mathrm{ml}$ and dilutions made at $12.5 \mu \mathrm{g} / \mathrm{ml}$.

2. Double antibiotic paste (DAP) - Equal amounts (250 $\mathrm{mg}$ tablets) of metronidazole and ciprofloxacin were mixed with distilled water $(1 \mathrm{~g} / \mathrm{mL})$.

3. Triple antibiotic paste (TAP) - Equal amounts (167 mg tablets) of metronidazole, ciprofloxacin and minocycline were mixed with distilled water (1 $\mathrm{g} / \mathrm{mL})$.

TAP and DAP were used as the positive control.

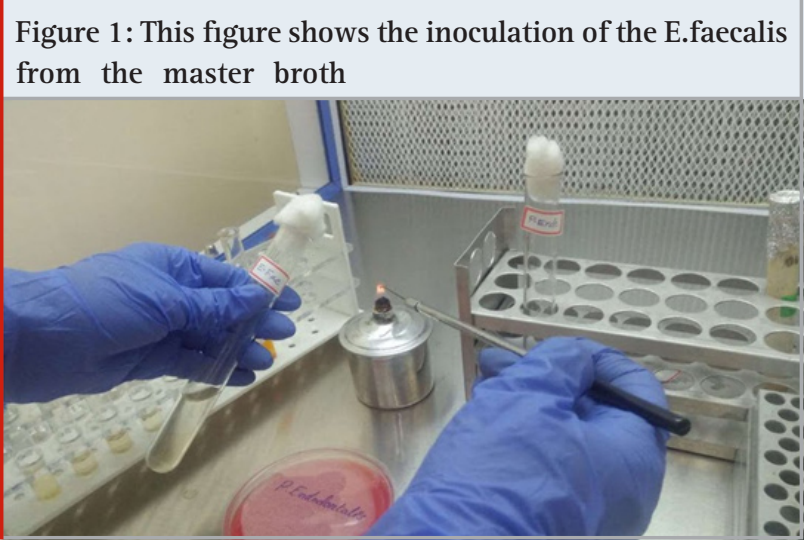

Microbial strains: Bacterial strains of gram positive Enterococcus Faecalis were obtained from ATCC 29212 that were cultured on Mueller Hinton broth. Bacterial growth of this master broth was confirmed by the presence of turbidity. Two millilitres of the sterilised Muller Hinton broth was inoculated with $50 \mu \mathrm{l}$ of $\mathrm{E}$. faecalis from the master broth and incubated at $37^{\circ} \mathrm{C}$ for $5 \mathrm{~h}$. The growth of bacteria was confirmed by the turbidity of the broth (Figure 1 and 3).

Figure 2: This figure demonstrates the incubation of the tubes for $12 \mathrm{hrs}$ and $24 \mathrm{hrs}$ at $37^{\circ} \mathrm{C}$

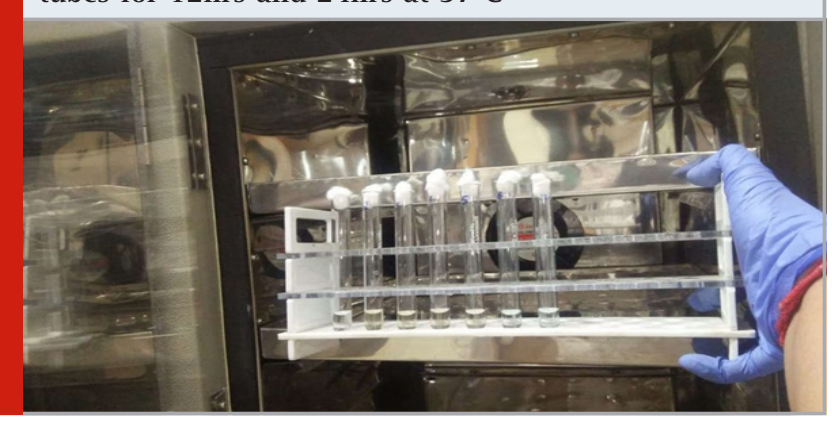


Experiment protocol: The tubes containing broth were divided into two time parameters for evaluation after $12 \mathrm{~h}$ and $24 \mathrm{~h}$. E.faecalis in the media without treatment served as controls for optical density (OD) evaluation. Tubes were divided into four groups each for evaluation at 12 and 24h (Figure 2).

Figure 3: This figure shows measuring the turbidity for confirmation of bacterial growth using a spectrophotometer

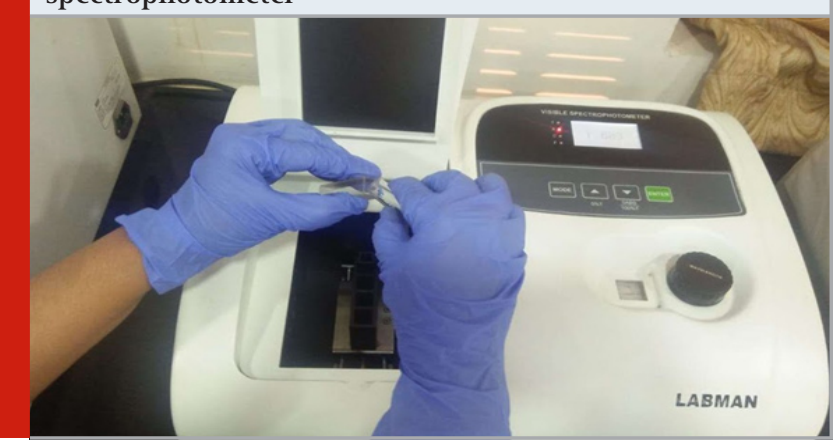

Group 1- Triple antibiotic paste $(50 \mu \mathrm{l})$ Group 2- Double antibiotic paste $(50 \mu \mathrm{l})$ Group 3- TAP $(25 \mu \mathrm{l})+$ pantoprazole $(25 \mu \mathrm{l})$ Group 4- DAP $(25 \mu \mathrm{l})+$ pantoprazole $(25 \mu \mathrm{l})$

As described above, the test solutions were added to the test tubes and incubated at $37^{\circ} \mathrm{C}$. The tubes were then evaluated for OD at $630 \mathrm{~nm}$ at 12 and $24 \mathrm{~h}$ after addition of test solutions, and the mean of five readings of each dilution was taken.

\section{RESULTS AND DISCUSSION}

In this study, the Mean microbial inhibition rates were expressed at $12 \mathrm{~h}$ and $24 \mathrm{~h}$ at three intervals and represented as Mean \pm SD. Statistical significance was determined by one-way analysis of variance (ANOVA) and post hoc least-significant difference test using SPSS software (version 22.0). $\mathrm{P}$ values less than 0.05 were considered significant. The results were statistically significant as compared with TAP group and the DAP group $\left({ }^{*} \mathrm{p}<0.001\right)$. Therefore, the results suggest that the TAP or its combination with PPIs can even be used at a lower concentration as it is statistically significant than DAP at $\mathrm{p}<0.001$, in order to avoid the deleterious effects associated with higher concentrations.

Therefore, It can be seen that, in TAP there is a higher amount of antibiotic sensitivity at $24 \mathrm{~h}$ concentration at the third interval with a mean inhibition rate of 0.294 \pm 0.03 (Figure 4). In DAP, there is a higher amount of the antibiotic sensitivity at $24 \mathrm{~h}$ concentration at the first interval with a mean inhibition rate of $0.215 \pm$ 0.20 (Figure 5). In $\mathrm{TAP}+\mathrm{PPi}$, there is an increase in the antibiotic sensitivity at $24 \mathrm{~h}$ concentration at the second interval with a mean inhibition rate of $0.195 \pm$
0.003 (Figure 6). In DAP+PPi, there is an increase in the antibiotic sensitivity at $24 \mathrm{~h}$ concentration at the second with a mean inhibition rate of $0.172 \pm 0.003$ (Figure 7). On association between mean antibiotic sensitivity (Abs) at $12 \mathrm{~h}$ and $24 \mathrm{~h}$ concentration of four types of antibiotic combinations at three different intervals, $\mathrm{TAP}+\mathrm{PPi}$ showed a highly significant inhibition at both the $12 \mathrm{~h}$ and $24 \mathrm{~h}$ concentration with a mean inhibition rate of 0.157 and 0.191 respectively with a $\mathrm{p}$ value of 0.001 $(<0.05)$, statistically significant association (Figure 8).

Figure 4: Bar graphs represent the antibiotic sensitivity (Abs) at $12 \mathrm{~h}$ and $24 \mathrm{~h}$ of Triple antibiotic paste (TAP) at three different intervals. $\mathrm{X}$ - axis represents the three different intervals of Triple antibiotic paste (TAP) and $\mathrm{Y}$-axis represents the mean inhibition rates. It can be seen that there is an increased amount of antibiotic sensitivity at $24 \mathrm{~h}$ concentration (red) at the third interval with a mean inhibition rate of 0.294

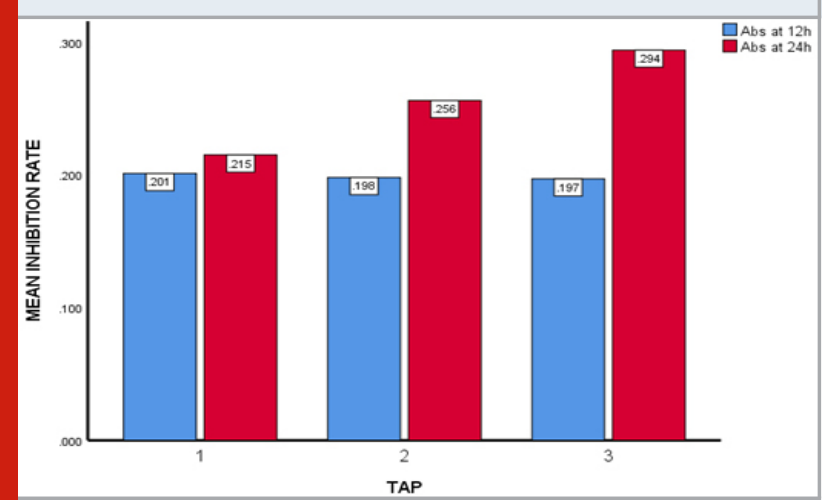

Figure 5: Bar graphs represent the antibiotic sensitivity (Abs) at $12 \mathrm{~h}$ and $24 \mathrm{~h}$ of Double antibiotic paste (DAP) at three different intervals. X-axis represents the three different intervals of Double antibiotic paste (DAP) and $\mathrm{Y}$-axis represents the mean inhibition rates. It can be seen that there is an increased amount of antibiotic sensitivity at $24 \mathrm{~h}$ concentration (red) at the first interval with a mean inhibition rate of 0.215

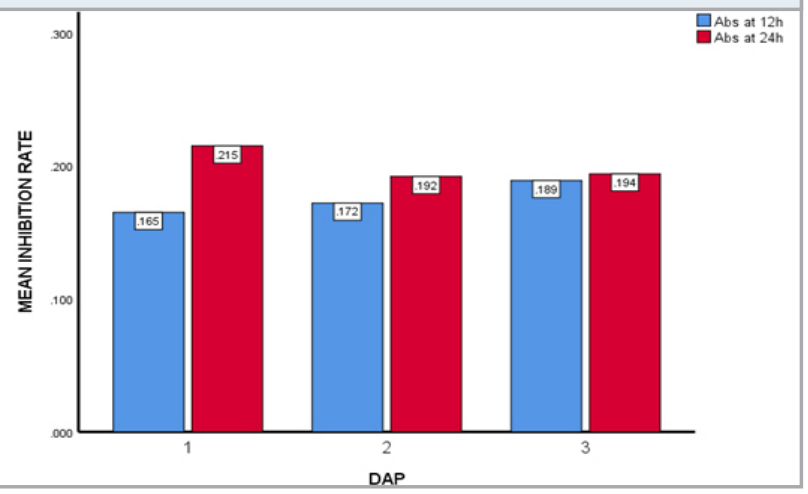

Generally, reinfection and failure of root canal treatment is due to the microorganisms in the periapical region. Studies prove TAP to be biocompatible (Gomes-Filho et al., 2012). Tetracycline group of drugs inhibits collagenases and 
matrix metalloproteinases and is not cytotoxic (Yao et al., 2007; Soory, 2008). They are known to increase the level of interleukin-10 which is an anti-inflammatory cytokine (Ramamurthy et al., 2002). Antibiotics such as metronidazole and ciprofloxacin have been proven to generate fibroblasts (Ferreira et al., 2010). TAP consists of metronidazole, minocycline, and ciprofloxacin and when used as an antimicrobial dressing, induces bleeding and creates a matrix for the growth of new vital tissue within the pulp canal (Hoshino et al., 1996).

Figure 6: Bar graphs represent the antibiotic sensitivity (Abs) at $12 \mathrm{~h}$ and $24 \mathrm{~h}$ of Triple antibiotic paste with a proton pump inhibitor (TAP+PPi) at three different intervals. X-axis represents the three different intervals of Triple antibiotic paste with a proton pump inhibitor $(\mathrm{TAP}+\mathrm{PPi})$ and $\mathrm{Y}$-axis represents the mean inhibition rates. It can be seen that there is an increase in the antibiotic sensitivity at $24 \mathrm{~h}$ concentration (red) at the second interval with a mean inhibition rate of 0.195 .

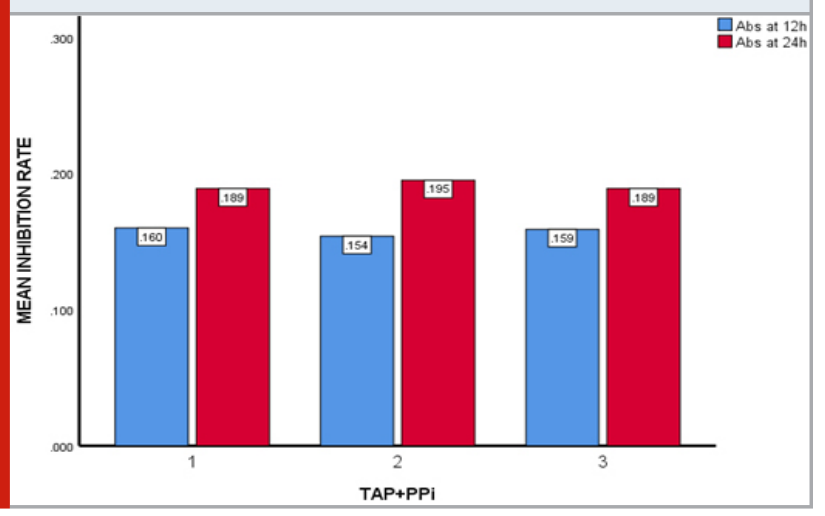

Figure 7: Bar graphs represent the antibiotic sensitivity (Abs) at $12 \mathrm{~h}$ and $24 \mathrm{~h}$ of Double antibiotic paste with a proton pump inhibitor $(\mathrm{DAP}+\mathrm{PPi})$ at three different intervals. $\mathrm{X}$-axis represents the three different intervals of Double antibiotic paste with a proton pump inhibitor (DAP+PPi) and $\mathrm{Y}$-axis represents the mean inhibition rates. It can be seen that there is an increase in the antibiotic sensitivity at $24 \mathrm{~h}$ concentration (red) at the second interval with a mean inhibition rate of 0.172 .

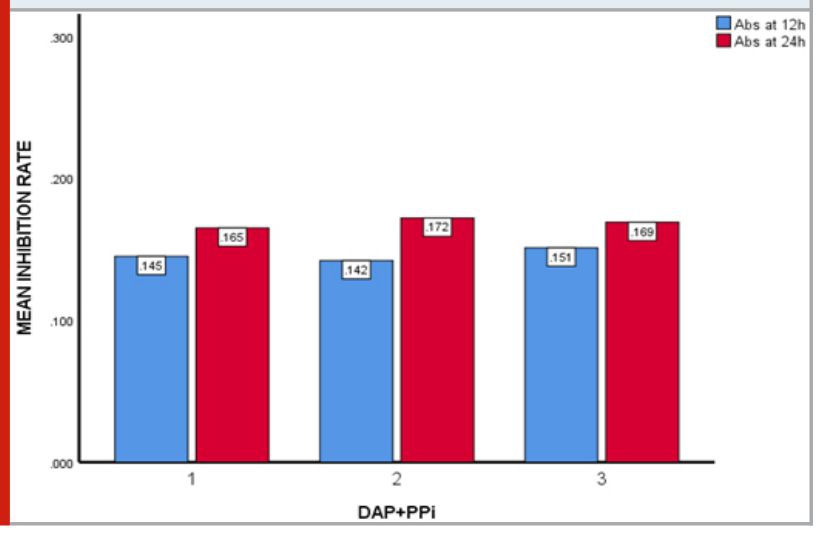

E.faecalis is known to express a proton pump in its plasma membrane for its energy metabolism and maintenance of constant cytoplasmic $\mathrm{pH}$, which enables the bacteria to maintain homeostasis of the cytoplasm (Booth, 1985; Kakinuma, 1987). PPIs exert both antibacterial and antiinflammatory properties along with the pro-reparative effects that enhance the healing of the periapical region (Kedika, Souza and Spechler, 2009). Studies show that removal of TAP from the canal using irrigation is much more difficult when compared to calcium hydroxide (Berkhoff et al., 2014). Therefore, as the success of the endodontic treatment lies upon the elimination of bacteria from the root canal, the future scope of this study was to evaluate the antibacterial efficacy of these drugs against other bacteria and fungi and evaluate its efficiency as an intracanal medicament.

Figure 8: Bar graph represents the association between the mean antibiotic sensitivity (Abs) at $12 \mathrm{~h}$ and $24 \mathrm{~h}$ concentration of four types of antibiotic combinations at three different intervals. X- axis represents the three different intervals of Triple antibiotic paste (TAP), Double antibiotic paste (DAP), Triple antibiotic paste with a proton pump inhibitor (TAP+PPi) and Double antibiotic paste with a proton pump inhibitor (DAP+PPi) whereas $\mathrm{Y}$-axis represents the mean inhibition rates. It can be seen that the mean inhibition rate of TAP is significant only at the $24 \mathrm{~h}$ concentration $(0.255)$, whereas TAP+PPi showed a highly significant inhibition at both the $12 \mathrm{~h}$ and $24 \mathrm{~h}$ concentration ( 0.157 and 0.191 respectively). DAP+PPi was found to be significant only at the $24 \mathrm{~h}$ concentration (0.160). Therefore, TAP or its combination with PPIs can be used at a lower concentration as it is statistically significant than DAP. [ ${ }^{*}$ p value- $0.001(<0.05)$, statistically significant association]

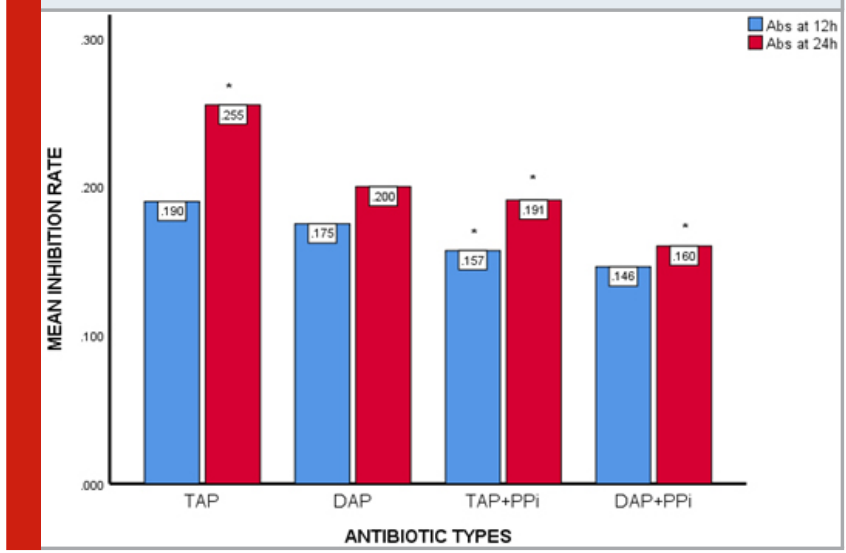

\section{CONCLUSION}

Therefore, within the limitations of this study, Triple antibiotic paste in combination with a proton pump inhibitor (TAP+PPi) showed significant and effective inhibition against bacterial strains of E.faecalis at both $12 \mathrm{~h}$ and $24 \mathrm{~h}$ concentration than TAP and DAP alone. 
Further studies have to be conducted for evaluation of other different combinations of antibiotics against E.faecalis.

\section{ACKNOWLEDGEMENTS}

The authors would like to acknowledge the support rendered by The Department of Conservative and Endodontic Dentistry of Saveetha Dental College and Hospitals and the management for their constant assistance with the research.

\section{Conflicts of Interest: There are no conflicts of interest.}

\section{REFERENCES}

Antony, D. P., Thomas, T. and Nivedhitha, M. S. (2020) 'Two-dimensional Periapical, Panoramic Radiography Versus Three-dimensional Cone-beam Computed Tomography in the Detection of Periapical Lesion After Endodontic Treatment: A Systematic Review', Cureus, 12(4), p. e7736.

Azeem, R. A. and Sureshbabu, N. M. (2018) 'Clinical performance of direct versus indirect composite restorations in posterior teeth: A systematic review', Journal of conservative dentistry: JCD, 21(1), pp. 2-9. Berkhoff, J. A. et al. (2014) 'Evaluation of triple antibiotic paste removal by different irrigation procedures', Journal of endodontia, 40(8), pp. 1172-1177.

Booth, I. R. (1985) 'Regulation of cytoplasmic pH in bacteria', Microbiological Reviews, pp. 359-378. doi: 10.1128/mmbr.49.4.359-378.1985.

Cotti, E., Mereu, M. and Lusso, D. (2008) 'Regenerative Treatment of an Immature, Traumatized Tooth With Apical Periodontitis: Report of a Case', Journal of Endodontics, pp. 611-616. doi: 10.1016/j. joen.2008.02.029.

Drusano, G. L. et al. (1986) 'Absolute oral bioavailability of ciprofloxacin', Antimicrobial Agents and Chemotherapy, pp. 444-446. doi: 10.1128/aac.30.3.444.

Ferreira, M. B. et al. (2010) 'Time- and concentrationdependent cytotoxicity of antibiotics used in endodontic therapy', Journal of Applied Oral Science, pp. 259-263. doi: 10.1590/s1678-77572010000300011.

Gomes-Filho, J. E. et al. (2012) 'Tissue Reaction to a Triantibiotic Paste Used for Endodontic Tissue Selfregeneration of Nonvital Immature Permanent Teeth', Journal of Endodontics, pp. 91-94. doi: 10.1016/j. joen.2011.09.020.

Govindaraju, L., Neelakantan, P. and Gutmann, J. L. (2017) 'Effect of root canal irrigating solutions on the compressive strength of tricalcium silicate cements', Clinical oral investigations, 21(2), pp. 567-571.

Gronthos, S. et al. (2002) 'Stem Cell Properties of Human Dental Pulp Stem Cells', Journal of Dental Research, pp. 531-535. doi: 10.1177/154405910208100806.

Hoshino, E. et al. (1996) 'In-vitro antibacterial susceptibility of bacteria taken from infected root dentine to a mixture of ciprofloxacin, metronidazole and minocycline', International Endodontic Journal, pp. 125-130. doi: 10.1111/j.1365-2591.1996.tb01173.x. Janani, K. and Sandhya, R. (2019) 'A survey on skills for cone beam computed tomography interpretation among endodontists for endodontic treatment procedure', Indian journal of dental research: official publication of Indian Society for Dental Research, 30(6), pp. 834-838.

Jenarthanan, S. and Subbarao, C. (2018) 'Comparative evaluation of the efficacy of diclofenac sodium administered using different delivery routes in the management of endodontic pain: A randomized controlled clinical trial', Journal of conservative dentistry: JCD, 21(3), pp. 297-301.

Kakinuma, Y. (1987) 'Lowering of cytoplasmic pH is essential for growth of Streptococcus faecalis at high pH', Journal of bacteriology, 169(9), pp. 4403-4405.

Kedika, R. R., Souza, R. F. and Spechler, S. J. (2009) 'Potential anti-inflammatory effects of proton pump inhibitors: a review and discussion of the clinical implications', Digestive diseases and sciences, 54(11), pp. 2312-2317.

Khandelwal, A. and Palanivelu, A. (2019) 'Correlation Between Dental Caries And Salivary Albumin In Adult Population In Chennai: An In Vivo Study', Brazilian Dental Science, 22(2), pp. 228-233.

Krithikadatta, J., Indira, R. and Dorothykalyani, A. L. (2007) 'Disinfection of Dentinal Tubules with 2\% Chlorhexidine, 2\% Metronidazole, Bioactive Glass when Compared with Calcium Hydroxide as Intracanal Medicaments', Journal of Endodontics, pp. 1473-1476. doi: 10.1016/j.joen.2007.08.016.

Malli Sureshbabu, N. et al. (2019) 'Concentrated Growth Factors as an Ingenious Biomaterial in Regeneration of Bony Defects after Periapical Surgery: A Report of Two Cases', Case reports in dentistry, 2019, p. 7046203.

Manohar, M. P. and Sharma, S. (2018) 'A survey of the knowledge, attitude, and awareness about the principal choice of intracanal medicaments among the general dental practitioners and nonendodontic specialists', Indian journal of dental research: official publication of Indian Society for Dental Research, 29(6), pp. 716-720.

Mohammadi, Z. et al. (2013) 'Microbial Biofilms in Endodontic Infections: An Update Review', Biomedical Journal, p. 59. doi: 10.4103/2319-4170.110400.

Mohammadi, Z., Giardino, L., et al. (2015) 'Agonistic and antagonistic interactions between chlorhexidine and other endodontic agents: A critical review', Iranian endodontic journal. Iranian Center for Endodontic Research, 10(1), p. 1.

Mohammadi, Z., Shalavi, S., et al. (2015) 'Impact of ultrasonic activation on the effectiveness of sodium hypochlorite: A review', Iranian endodontic journal. Iranian Center for Endodontic Research, 10(4), p. 216. Mohammadi, Z. et al. (2017) 'Recent advances in 
root canal disinfection: a review', Iranian endodontic journal. Iranian Center for Endodontic Research, 12(4), p. 402.

Nandakumar, M. and Nasim, I. (2018) 'Comparative evaluation of grape seed and cranberry extracts in preventing enamel erosion: An optical emission spectrometric analysis', Journal of conservative dentistry: JCD, 21(5), pp. 516-520.

Nerwich, A., Figdor, D. and Messer, H. H. (1993) 'pH changes in root dentin over a 4-week period following root canal dressing with calcium hydroxide', Journal of Endodontics, pp. 302-306. doi: 10.1016/s00992399(06)80461-9.

Pinky, C., Subbareddy, V. V. and Shashibhushan, K. K. (2011) 'Endodontic treatment of necrosed primary teeth using two different combinations of antibacterial drugs: An in vivo study', Journal of Indian Society of Pedodontics and Preventive Dentistry, p. 121. doi: 10.4103/0970-4388.84684.

Poorni, S., Srinivasan, M. R. and Nivedhitha, M. S. (2019) 'Probiotic strains in caries prevention: A systematic review', Journal of conservative dentistry: JCD, 22(2), pp. 123-128.

Rajakeerthi, R. and Ms, N. (2019) 'Natural Product as the Storage medium for an avulsed tooth - A Systematic Review', Cumhuriyet Dental Journal, 22(2), pp. 249256.

Rajendran, R. et al. (2019) 'Comparative Evaluation of Remineralizing Potential of a Paste Containing Bioactive Glass and a Topical Cream Containing Casein Phosphopeptide-Amorphous Calcium Phosphate: An in Vitro Study', Pesquisa brasileira em odontopediatria e clinica integrada, 19(1), pp. 1-10.

Ramamurthy, N. S. et al. (2002) 'Inhibition of Matrix Metalloproteinase-Mediated Periodontal Bone Loss in Rats: A Comparison of 6 Chemically Modified Tetracyclines', Journal of Periodontology, pp. 726-734. doi: 10.1902/jop.2002.73.7.726.

Ramarao, S. and Sathyanarayanan, U. (2019) 'CRA Grid - A preliminary development and calibration of a paper-based objectivization of caries risk assessment in undergraduate dental education', Journal of conservative dentistry: JCD, 22(2), pp. 185-190.

Saad, A. Y. and Yousef Saad, A. (1988) 'Calcium hydroxide and apexogenesis', Oral Surgery, Oral Medicine, Oral Pathology, pp. 499-501. doi: 10.1016/00304220(88)90277-0.

Sato, I. et al. (1996) 'Sterilization of infected rootcanal dentine by topical application of a mixture of ciprofloxacin, metronidazole and minocycline in situ', International endodontic journal, 29(2), pp. 118-124. Siddique, R. et al. (2019) 'Qualitative and quantitative analysis of precipitate formation following interaction of chlorhexidine with sodium hypochlorite, neem, and tulsi', Journal of conservative dentistry: JCD, 22(1), pp. 40-47.

Siddique, R. and Nivedhitha, M. S. (2019) 'Effectiveness of rotary and reciprocating systems on microbial reduction: A systematic review', Journal of conservative dentistry: JCD, 22(2), pp. 114-122.

Siddique, R., Nivedhitha, M. S. and Jacob, B. (2019) 'Quantitative analysis for detection of toxic elements in various irrigants, their combination (precipitate), and para-chloroaniline: An inductively coupled plasma mass spectrometry study', Journal of conservative dentistry: JCD, 22(4), pp. 344-350.

Soory, M. (2008) 'A role for non-antimicrobial actions of tetracyclines in combating oxidative stress in periodontal and metabolic diseases: a literature review', The open dentistry journal, 2, pp. 5-12.

Teja, K. V., Ramesh, S. and Priya, V. (2018) 'Regulation of matrix metalloproteinase-3 gene expression in inflammation: A molecular study', Journal of conservative dentistry: JCD, 21(6), pp. 592-596.

Windleyiii, W. et al. (2005) 'Disinfection of Immature Teeth with a Triple Antibiotic Paste', Journal of Endodontics, pp. 439-443. doi: 10.1097/01.don.0000148143.80283. ea.

Yao, J. S. et al. (2007) 'Comparison of doxycycline and minocycline in the inhibition of VEGF-induced smooth muscle cell migration', Neurochemistry International, pp. 524-530. doi: 10.1016/j.neuint.2006.10.008. 